\title{
Localization of Macrophage Migration Inhibitory Factor (MIF) to Secretory Granules within the Corticotrophic and Thyrotrophic Cells of the Pituitary Gland
}

\author{
Toshihiko Nishino,* Jürgen Bernhagen, ${ }^{\dagger}$ Hideo Shiiki,* \\ Thierry Calandra, ${ }^{\dagger}$ Kazuhiro Dohi, ${ }^{*}$ Richard Bucala $^{\dagger}$ \\ *First Department of Internal Medicine, Nara Medical University, \\ Nara, Japan \\ †Picower Institute for Medical Research, Manhasset, New York, \\ U.S.A.
}

\begin{abstract}
Background: Macrophage migration inhibitory factor (MIF) was one of the first lymphokine activities to be discovered and was described almost 30 years ago to be a soluble factor(s) produced by activated T lymphocytes. In more recent studies, MIF has been "rediscovered" to be an abundant, pre-formed constituent of the anterior pituitary gland and the macrophage, and to be a critical component in the host response to septic shock. Pituitary-derived MIF enters the circulation after infectious or stressful stimuli and appears to act to counterregulate glucocorticoid suppression of cytokine production.

Materials and Methods: Immunoelectron microscopy utilizing a combination of anti-MIF and anti-pituitary hormone-specific antibodies was used to study the ultrastructural localization of MIF within the anterior pituitary gland. Pituitaries were obtained from resting, unstimulated mice and from mice $16 \mathrm{hr}$ after endotoxin administration. The release of MIF also was investigated in vitro by examining the effect of corticotropin-releasing hormone (CRH) on the AtT-20, corticotrophic cell line.
\end{abstract}

Results: MIF localizes to granules present exclusively in ACTH and TSH secreting cells. Within each cell type, a subset of granules was found to contain both MIF and ACTH, or MIF and TSH. The pituitary content of MIFcontaining granules decreased significantly after experimentally induced endotoxemia. In seven pituitaries examined $16 \mathrm{hr}$ after LPS injection, the number of MIFpositive granules diminished by $38 \%$ in corticotrophic cells and by $48 \%$ in thyrotrophic cells when compared with controls $(p<0.05)$. CRH was observed to be a potent MIF secretagogue in vitro, inducing the release of MIF from corticotrophic cells at concentrations lower than that required for ACTH release.

Conclusion: These data provide ultrastructural information that identify MIF to be a novel anterior pituitary hormone, support earlier studies showing a time-dependent release of pituitary MIF during endotoxemia, and suggest an important, systemic role for MIF in the stress response to infection and other stimuli.

\section{INTRODUCTION}

The protein mediator known as macrophage migration inhibitory factor (MIF) was described originally to be a factor released by activated $\mathrm{T}$ lymphocytes which inhibited the random migration of macrophages in vitro $(1,2)$. For almost 30

Address correspondence and reprint requests to: Richard Bucala, The Picower Institute for Medical Research, 350 Community Avenue, Manhasset, NY 11030, U.S.A. years, however, the specific biological functions of MIF were unknown, and an appreciation of the important physiological role of this protein has emerged only recently. For instance, significant quantities of pre-formed MIF protein have been identified to be present in the anterior pituitary gland and in monocytes/macrophages and to be released into the bloodstream in response to invasive stimuli $(3,4)$. MIF plays a pivotal role in the host response to endotoxic shock, 
and the administration of neutralizing anti-MIF antibodies fully protects animals from lethal endotoxemia (3). Within this context, purified recombinant MIF exhibits several important proinflammatory functions. It induces tumor necrosis factor $\alpha$ (TNF $\alpha)$ release from macrophages, acts together with interferon- $\gamma$ (IFN $\gamma$ ) to promote nitric oxide release, and augments the macrophage killing of intracellular pathogens $(4,5)$. In distinct contrast to other pro-inflammatory mediators however, the observation has been made that glucocorticoids, at low concentrations, induce rather than inhibit MIF production from monocytes/macrophages and T cells (6). The MIF which is released from immune cells then acts to "override" the suppressive effect of steroids on cytokine production, indicating that MIF functions physiologically as a counterregulatory mediator to modulate glucocorticoid effects on inflammation and immunity.

The identification of a significant, pituitary source of MIF led us to investigate more closely the ultrastructural location of MIF protein within anterior pituitary cells in vivo. Although mouse MIF first was isolated from the secretory products of a corticotrophic cell line, the sites of MIF production and release from within pituitary gland in vivo have not been precisely established. In the present study, we performed immunoelectron microscopy of mouse pituitary glands that had been stained both with anti-recombinant MIF and with specific anti-ACTH, -TSH, -FSH, -GH, -LH, or -PRL antibodies. MIF was localized to granules contained within ACTH- and TSHsecreting cells and was observed to be released from these cells during endotoxemia. In vitro studies established that $\mathrm{CRH}$ is a potent MIF secretogogue, inducing the release of MIF at concentrations lower than that required for ACTH release.

\section{MATERIALS AND METHODS}

\section{Animals}

Fourteen male BALB/c mice, weighing 25-30 g each, were purchased from Japan SLC Inc. (Hamamatu, Japan). In seven mice, endotoxemia was induced by the intraperitoneal injection of $2.25 \mathrm{mg} / \mathrm{kg}$ of Escherichia coli 0111:B4 lipopolysaccharide (LPS; Difco Laboratories, Detroit, MI, U.S.A.). Seven saline-injected mice served as controls. All animals were killed by cervical dislocation, and the pituitary gland was immediately removed for processing as described below.

\section{Immunochemicals}

Rabbit polyclonal anti-MIF antiserum was raised to purified, mouse recombinant MIF (rMIF) as described previously (3). The anti-pituitary hormone antisera comprised the following reagents: rabbit anti-human ACTH (cross-reactive with mouse ACTH, Zymed Laboratories, San Francisco, CA, U.S.A.), rabbit anti-rat FSH, monkey anti-rat $\mathrm{GH}$, rabbit anti-rat $\mathrm{LH}$, rabbit anti-rat PRL (each obtained from the U.S. National Hormone and Pituitary Program, NIDDK-NIH), and rabbit anti-mouse TSH (UCB-Bioproducts S.A., Drogenbos, Belgium).

\section{Immunoelectron Microscopy}

Electron microscopy studies were performed on a Hitachi JEM-1200EX instrument. Pituitary glands were fixed for $2 \mathrm{hr}$ at $4^{\circ} \mathrm{C}$ in a solution consisting of $4 \%$ paraformaldehyde and $0.15 \%$ glutaraldehyde dissolved in $0.1 \mathrm{M}$ phosphate buffer ( $\mathrm{pH}$ 7.4). Fixed tissue was embedded in LR White (London Resin Co., Hampshire, United Kingdom) and ultrathin sections prepared and mounted on nickel grids. Double immunostaining was performed on each side of the grid, as described previously (7). Briefly, one side of the grid was treated first with $1 \%$ bovine serum albumin in $0.1 \mathrm{M}$ phosphate buffer (PBS-BSA) for $5 \mathrm{~min}$ and then with $5 \%$ normal goat serum at room temperature for $5 \mathrm{~min}$. Anti-MIF antiserum was applied to sections at a dilution of $1 / 300$ and incubated for $2 \mathrm{hr}$. The sections then were washed, treated with $10 \mathrm{~nm}$ gold-labeled anti-rabbit IgG for 30 min (Amersham Japan Co., Tokyo, Japan), washed again with $1 \%$ PBS-BSA three times, and dried at room temperature. After re-equilibration in $1 \%$ PBS-BSA and treatment with normal goat serum for $5 \mathrm{~min}$, the anti-pituitary hormone antisera were applied on the other side of the grid and incubated for $2 \mathrm{hr}$. The final antibody dilutions were 1/30 for antiACTH, anti-TSH, anti-FSH, anti-GH, and anti-LH antisera, and 1/40 for the anti-PRL antiserum. The sections then were washed and treated with $20 \mathrm{~nm}$ gold-labeled protein $\mathrm{G}$ or anti-rabbit IgG (Amersham Japan). After extensive washing, the sections were counterstained with uranyl acetate. As an additional control for MIF immunoreactivity, positively stained sections were subjected to blocking experiments in which anti-MIF anti- 
serum first was incubated with purified, mouse MIF $(0.01-1 \mu \mathrm{g} / \mathrm{ml})$ for $1 \mathrm{hr}$ at $37^{\circ} \mathrm{C}$. Sections stained with anti-MIF antiserum that had been pre-incubated in this manner were uniformly negative.

For morphological studies, the pituitary gland was fixed in $2.5 \%$ glutaraldehyde in $0.1 \mathrm{M}$ PBS. The tissue then was immersed in $1 \%$ osmium tetroxide for post-fixation. The specimens were dehydrated with a graded ethanol series, embedded in Epon 812, and ultrathin sections prepared and stained with uranyl acetate and lead citrate.

Gold-labeled granules were quantified by stereoscopic microscopy of electron micrographs obtained at the magnification of 5,000×. Each scored cell contained 200-300 gold-labeled granules. Statistical analyses were performed using the Mann-Whitney's $U$ test (8).

\section{In Vitro Studies}

The mouse corticotrophic cell line AtT-20 was obtained from American Type Culture Collection (Rockville, MD, U.S.A.) and cultured in RPMI/ $1 \%$ fetal bovine serum supplemented with gentamicin $(50 \mu \mathrm{g} / \mathrm{ml})$. Synthetic rat CRH was obtained from Calbiochem (La Jolla, CA, U.S.A.) and determined to contain negligible quantities of endotoxin ( $15 \mathrm{pg}$ of LPS/ $\mu \mathrm{g}$ protein) as assessed by the Limulus amoebocyte assay (BioWhittaker Inc., Walkersville, MD, U.S.A.). For stimulation studies, $1 \times 10^{6}$ cells were cultured in 6-well plates ( $1 \mathrm{ml}$ total volume) together with CRH $(0.01-1000 \mathrm{ng} / \mathrm{ml})$ for $16 \mathrm{hr}$. The conditioned media then were removed and analyzed for MIF content by a sensitive, MIF-specific sandwich ELISA (C. N. Metz, in preparation) and for ACTH content by radioimmunoassay (ICN, Inc., Costa Mesa, CA, U.S.A.).

\section{RESULTS}

In pituitaries obtained from unstimulated, control mice, positive staining for MIF was localized to small secretory granules, which ranged in size from 90 to $200 \mathrm{~nm}$ in diameter (Figs. 1 and 2). The MIF-containing cells appeared throughout the anterior lobe, but were distributed in highest concentration in the central portions and more sparsely in the periphery. Positive cells also showed a tendency to abut capillaries. No MIFpositive granules were detected in the posterior lobe.

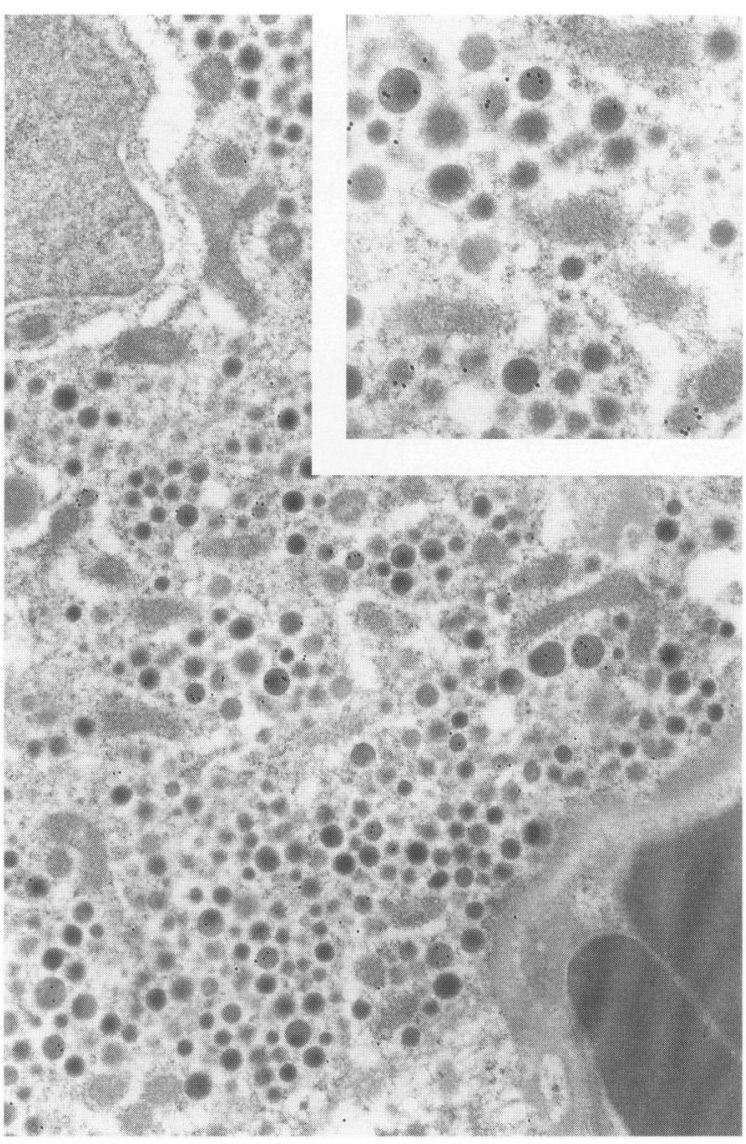

FIG. 1. Immunoelectron micrograph showing one representative MIF-containing, corticotrophic cell adjoining a capillary $(12,000 \times)$

The higher magnification inset $(22,000 \times)$ shows gold-labeled anti-MIF antibodies localized within small granules.

We then sought to determine whether MIF was coexpressed with classical anterior pituitary hormones by examining sections in which the anti-MIF and the anti-pituitary hormone antibodies were labeled with two differently sized gold particles (10 and $20 \mathrm{~nm}$, respectively). As shown in Figs. 3-5, MIF-positive granules colocalized exclusively to cells that stained with either anti-ACTH or anti-TSH antibodies. By contrast, cells identified to contain FSH, GH, LH, and PRL secretory granules showed no staining for MIF (Fig. 6).

The ACTH-secreting cells comprised two subtypes which followed the morphological classification of Kurosumi et al. (9). The first type of cells were oval in shape, displayed a few stout processes, and contained secretory granules which filled the entire cytoplasm (Fig. 3). The second corticotrophic cell type consisted of small 


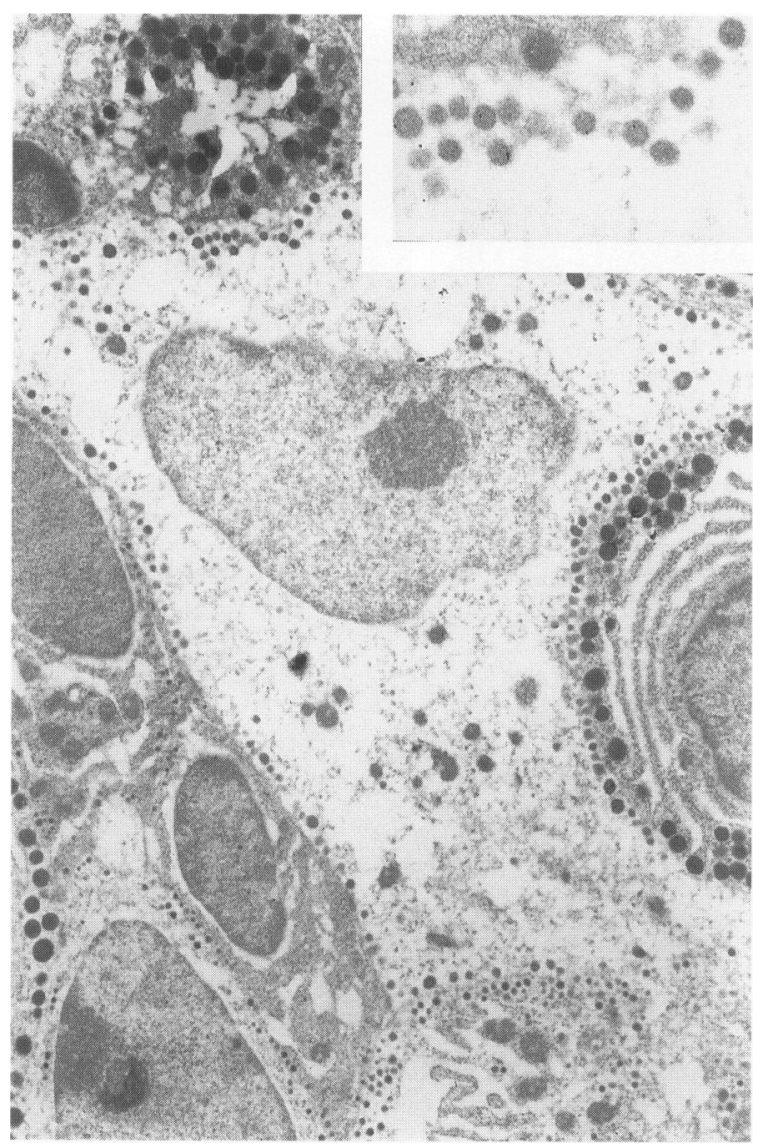

FIG. 2. Immunoelectron micrograph showing a second representative MIF-containing, corticotrophic cell in which the secretory granules are arranged along the cell periphery $(12,000 \times$, inset: $22,000 \times$ ).

satellite cells with slender processes and secretory granules aligned in a row-like fashion against the outer cell membrane (Fig. 4). Both cell types contained an abundance of MIF-positive secretory granules. Interestingly, three distinct types of secretory granules were identified within each cell type: those containing MIF alone, those containing ACTH alone, and those containing both MIF and ACTH.

Morphologically, the TSH-secreting cells showed a well-developed endoplasmic reticulum and a large number of small secretory granules which ranged in size from 150 to $200 \mathrm{~nm}$ in diameter (Fig. 5). As in the case of the MIFcontaining corticotrophic cells, three types of secretory granules were identified within these cells: those containing MIF alone, those containing TSH alone, and those containing both MIF and TSH.

The release of MIF was investigated by ex-

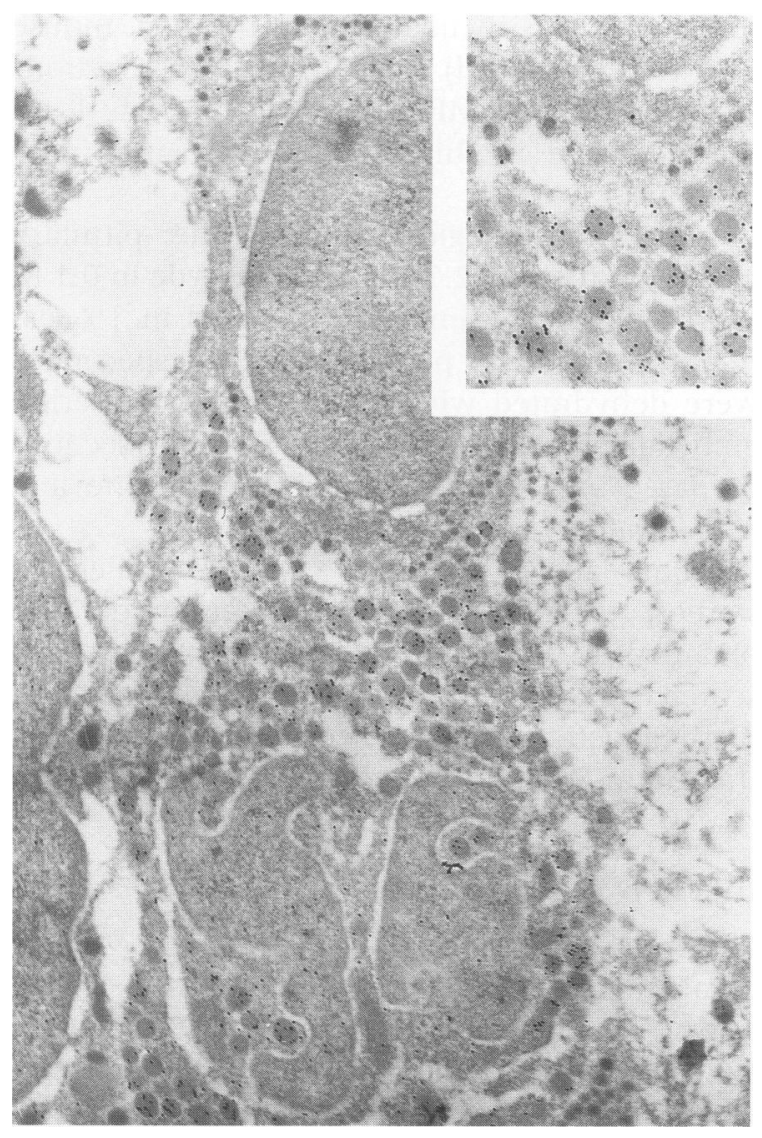

FIG. 3. Electron micrograph of a Type I corticotrophic cell double-labeled with anti-MIF antibody (10-nm gold particles) and anti-ACTH antibody (20-nm gold particles)

(Inset) Secretory granules containing MIF alone, ACTH alone, and both MIF and ACTH $(14,000 \times$, inset: $22,000 \times$ ).

amining MIF localization in pituitary glands that were obtained from seven mice $16 \mathrm{hr}$ after endotoxin injection, a time that corresponds to high circulating MIF levels $(3,4)$. A significant decrease in the total number of MIF-containing granules was evident in both the corticotrophic and the thyrotrophic cell types when endotoxintreated mice were compared with control mice (Fig. 7). The number of MIF-positive granules fell by $38 \%$ in corticotrophic cells and by $48 \%$ in thyrotrophic cells $(p<0.05)$. When the granule subtypes were further quantified, the most significant decreases in MIF content occurred only in the granule populations that contained MIF alone (Table 1).

Finally, to begin to obtain insight into the role of hypothalamic releasing factors in the release of MIF from pituitary cells, we studied the 


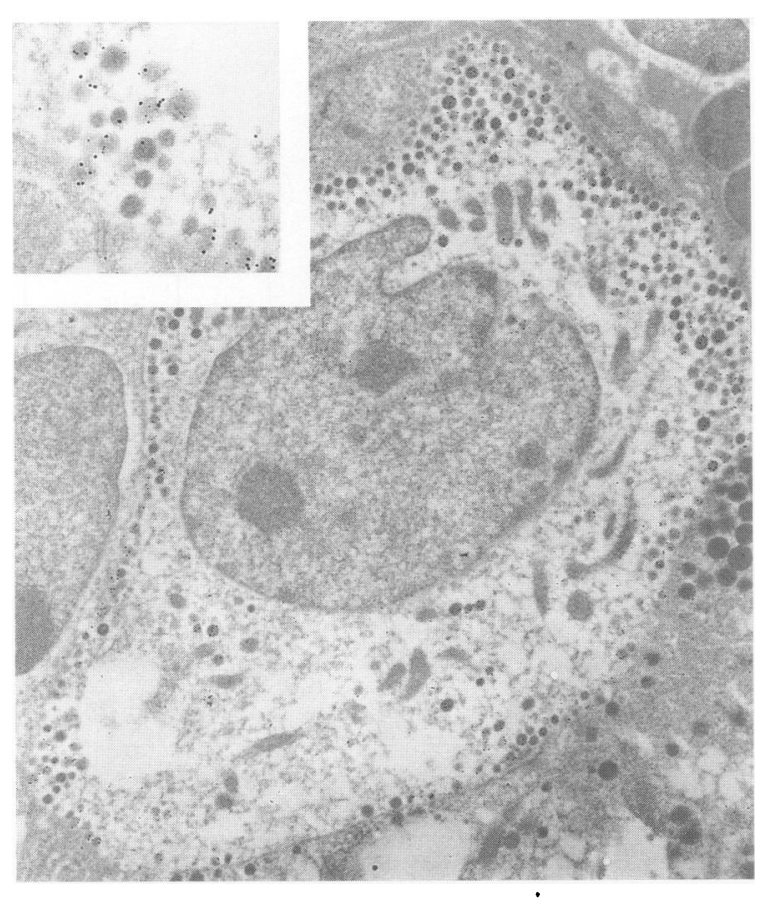

FIG. 4. Immunoelectron micrograph of a Type II corticotrophic cell double-labeled with antiMIF antibody (10 nm gold particles) and antiACTH antibody (20 nm gold particles) (14,000X, inset: $22,000 \times)$.

effect of CRH on MIF secretion by the mouse AtT-20 corticotrophic cell line. As previously reported $(10,11)$, peak ACTH release by these cells was observed at a CRH concentration of approximately $100 \mathrm{ng} / \mathrm{ml}$ (Table 2). CRH also was identified in these experiments to be a potent MIF secretogogue, stimulating MIF release at concentrations that were much lower than that required for peak ACTH secretion.

\section{DISCUSSION}

The present study provides the first anatomic and morphological confirmation of recent data indicating that MIF is a prominent, pre-formed constituent of the anterior pituitary gland which is released during circumstances such as endotoxic shock (3). Significant quantities of MIF are present within the secretory granules contained within the corticotrophic and the thyrotrophic cell populations, which comprise 20 and $5 \%$ of the adenohypophyseal cells, respectively. Since the N-terminal sequence of mouse MIF first was obtained from a protein isolated from the secretory products of the AtT-20 corticotrophic cell

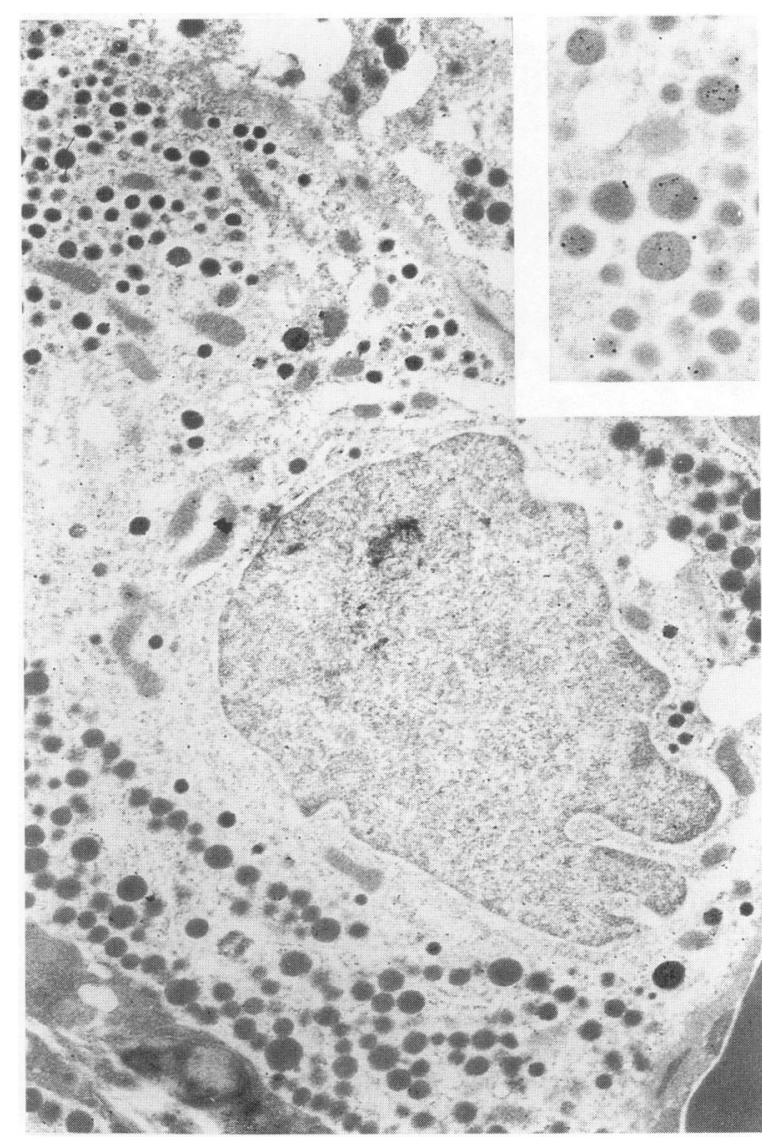

FIG. 5. Immunoelectron micrograph of a representative thyrotrophic cell labeled with antiMIF (10-nm gold particles) and anti-TSH antibodies (20-nm gold particles) $(10,000 \times$, inset: 22,000x).

line (3), the localization of immunoreactive MIF to this cell type in vivo is not surprising. The identification of significant quantities of MIF in the granules of thyrotrophic cells was not expected, although in a prior report TSH-containing cells were found to also contain immunoreactive quantities of the cytokine interleukin- $1 \beta$ (12). Interestingly, thyrotrophic and corticotrophic cells localize predominantly to the central or mucoid wedge of the anterior lobe (13), suggesting that MIF expression may be limited anatomically to this region of the anterior pituitary gland. These data also point to a potentially important physiological relationship between MIF and TSH. This may involve an autocrine effect of MIF on TSH release or possibly, a regulatory role for MIF in thyroid hormone responses similar to what has been described to occur within the glucocorticoid and immune systems. In that context, glucocorticoids directly induce MIF release, 

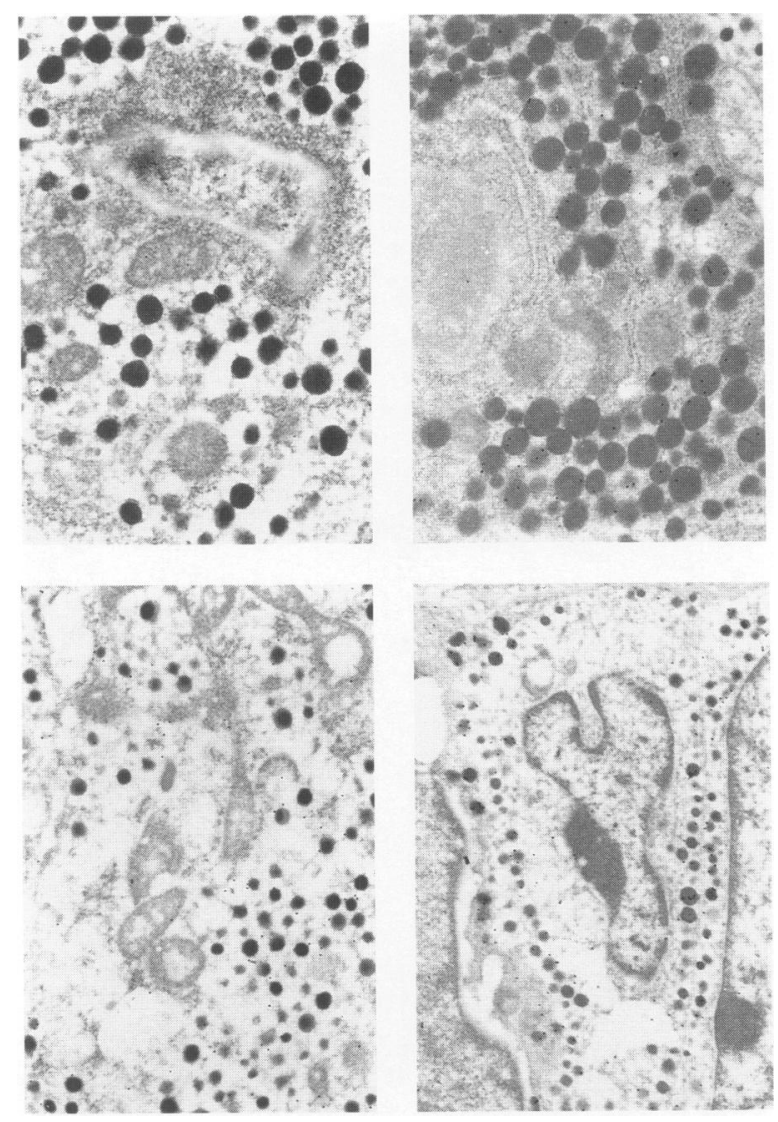

FIG. 6. Immunoelectron micrographs showing representative GH (upper left)- FSH (upper right)- PRL (bottom left)-, and LH (bottom right)-secreting cells

MIF-specific staining was not observed in these cell types $(14,000 \times)$.

which then acts to override the inhibitory effect of glucocorticoids on immune cell cytokine expression (6).

The marked decrease in the number of MIFcontaining granules after endotoxin administration is consistent with prior Western blotting analyses which showed a significant fall in total pituitary MIF content during endotoxic shock (3). Although endotoxemia is associated with the release of ACTH and a prominent glucocorticoid stress response, a significant decrease in the pituitary content of ACTH-containing granules was not observed in the present study. This may be due to relative differences in the time course of the release and synthesis of MIF versus ACTH, which might not have been detectable in the single ( $16 \mathrm{hr}$ ) time point that was studied.

Many of the effects of endotoxin on pituitary function have been attributed to the ability of

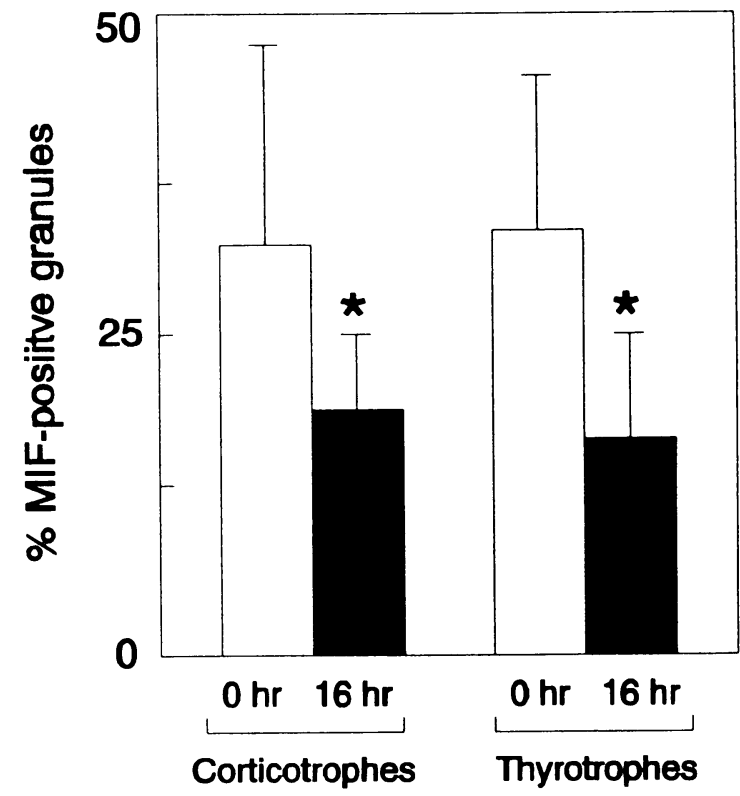

FIG. 7. Relative changes observed in MIF-containing granules in corticotrophic and thyrotrophic cells $16 \mathrm{hr}$ after endotoxin administration

Gold-labeled granules were quantified by stereoscopic microscopy of electron micrographs as described in Materials and Methods. Seven pituitaries were analyzed for each time point. The relative percentage change in MIF staining was calculated by the formula: (MIF-positive gold-labeled granules/ total gold-labeled granules) $\times 100$. In corticotrophic cells, the total number of gold-labeled granules observed was $200.9 \pm 101.3$ and $163.5 \pm 81.9$ at 0 and $16 \mathrm{hr}$ respectively ( $p=$ NS), and in thyrotrophic cells: $212.6 \pm 114.7$ and $244.7 \pm 104.2$ at 0 and 16 hr respectively $(p=\mathrm{NS})$. ${ }^{*} p<0.05$ as analyzed by the Mann-Whitney $U$ test.

IL- $1 \beta$, TNF $\alpha$, or IL- 6 to promote the release of hypothalamic releasing factors such as $\mathrm{CRH}(14-$ 17). It should be noted however, that LPS in subnanogram concentrations can directly induce MIF release from primary pituitary cells or the AtT-20 corticotrophic cell line in vitro (Ref. 3 and unpublished observations). Recent studies performed in rats with lesions of the paraventricular nucleus so as to eliminate hypothalamic responses suggest that LPS also may bypass classical pathways of pituitary activation in vivo to elicit ACTH production (18). These data do not exclude a primary role for $\mathrm{CRH}$ (or other hypothalamic releasing factors) in the induction of MIF release during stress or tissue invasion, and data obtained with the AtT-20 corticotrophic cell line indicate that $\mathrm{CRH}$ is an extremely potent MIF secretogogue in vitro. Nevertheless, the 
TABLE 1. Analysis of secretory granule content in corticotrophic and thyrotrophic cells before and after endotoxin administration

\begin{tabular}{lcr}
\hline & & Time \\
\cline { 2 - 3 } Granule Content & $\mathbf{0 ~ h r}$ & $\mathbf{1 6} \mathbf{~ h r}$ \\
\hline Corticotrophes & & $4.9 \pm 4.4(p<0.05)$ \\
MIF alone (\%) & $8.1 \pm 3.9$ & $15.1 \pm 5.8(p=\mathrm{NS})$ \\
MIF + ACTH (\%) & $24.4 \pm 17.5$ & $80.0 \pm 9.2(p=\mathrm{NS})$ \\
ACTH alone (\%) & $67.5 \pm 18.3$ & $8.6 \pm 4.4(p<0.05)$ \\
Thyrotrophes & & $9.1 \pm 5.0(p=\mathrm{NS})$ \\
MIF alone $(\%)$ & $20.1 \pm 10.1$ & $82.3 \pm 8.2(p=\mathrm{NS})$ \\
MIF + TSH $(\%)$ & $13.7 \pm 9.1$ & $66.3 \pm 13.4$ \\
TSH alone $(\%)$ & & \\
\end{tabular}

Cells were stained with anti-MIF-anti-ACTH- and anti-TSH-labeled gold particles and quantified as described in the legend to Fig. 7 and Materials and Methods.

identity of the proximal mediator(s) responsible for inducing MIF release during various physiological and pathophysiological circumstances remain to be elucidated. Investigations into this question will be complicated by the observation that MIF exists within both corticotrophic and thyrotrophic cells and that it is packaged in two distinct granular subtypes, one containing MIF alone and one containing both MIF and ACTH or MIF and TSH. These subtypes may reflect an ordered pattern of granule development, where

TABLE 2. Total ACTH and MIF content in conditioned medium obtained $16 \mathrm{hr}$ after stimulation of $1 \times 10^{6} \mathrm{AtT}-20$ cells with the indicated concentrations of $\mathrm{CRH}$

\begin{tabular}{ccc}
\hline CRH (ng/ml) & ACTH (ng/ml) & MIF (ng/ml) \\
\hline 1000 & 15.0 & 6.4 \\
100 & 22.3 & 6.2 \\
10 & 10.7 & 7.5 \\
1 & 9.3 & 8.8 \\
0.1 & 4.4 & 12.0 \\
0.01 & - & 5.5
\end{tabular}

ACTH was measured by a commercial radioimmunoassay. The MIF values were obtained by sandwich ELISA and are the mean of triplicate measurements. granules containing MIF or ACTH/TSH alone mature over time to secretory granules that contain both mediators. Alternatively, these granules may represent distinct subtypes within each cell that function independently and which are released in response to granule-specific stimuli or releasing factors.

It has been discovered recently that MIF is released directly from immune cells following stimulation with physiological concentrations of glucocorticoids (6). At the level of a localized inflammatory site, immune cell MIF acts to balance or counterregulate the anti-inflammatory or immunosuppressive of glucocorticoids. which appear in the circulation as an integral part of the generalized stress response to pain or tissue invasion. The fact that pro-inflammatory stimuli such as endotoxin also lead to the pituitary release of MIF points to the ability of the host to provide a central, counterregulatory response which may serve to balance glucocorticoid effects at the systemic level as well.

\section{ACKNOWLEDGMENTS}

We are grateful to Drs. C. Metz and M. Wuttke for performing the MIF ELISA and AtT-20 experiments and to Dr. A. Cerami for helpful discussions. This work was supported by National Institutes of Health Grant AI35931. 


\section{REFERENCES}

1. Bloom BR, Bennett B. (1966) Mechanism of a reaction in vitro associated with delayedtype hypersensitivity. Science 153: 80-82.

2. David J. (1966) Delayed hypersensitivity in vitro: Its mediation by cell-free substances formed by lymphoid cell-antigen interaction. Proc. Natl. Acad. Sci. U.S.A. 56: 72-77.

3. Bernhagen J, Calandra T, Mitchell RA, et al. (1993) MIF is a pituitary-derived cytokine that potentiates lethal endotoxaemia. Nature 365: 756-759.

4. Calandra T, Bernhagen J, Mitchell RA, Bucala R. (1994) The macrophage is an important and previously unrecognized source of macrophage migration inhibitory factor. $J$. Exp. Med. 179: 1895-1902.

5. Bernhagen J, Mitchell RA, Calandra $T$, Voelter W, Cerami A, Bucala R. (1994) Purification, bioactivity, and secondary structure analysis of mouse and human macrophage migration inhibitory factor (MIF). Biochemistry 33: 14144-14155.

6. Calandra T, Bernhagen J, Metz CN, et al. (in press). Identification of MIF as a glucocorticoid-induced mediator and counter-regulator of glucocorticoid inhibition of cytokine production. Nature.

7. Bendayan M. (1982) Double immunocytochemical labeling applying the protein Agold technique. J. Histochem. Cytochem. 30: 81-85.

8. Zar JH. (1984) Biostatistical Analysis. PrenticeHall, Englewood Cliffs, NJ.

9. Kurosumi K. (1986) Cell classification of the rat anterior pituitary by means of immunoelectron microscopy. J. Clin. Electron Microscopy 19: 299-319.

10. Hook VYH, Heisler S, Sabol SL, Axelrod J. (1982) Corticotropin releasing factor stimu- lates adrenocorticotropin and $\beta$-endorphin release from AtT-20 mouse pituitary cells. Biochem. Biophys. Res. Commun. 106: 13641371.

11. Axelrod J, Reisine TD. (1984) Stress hormones: Their interaction and regulation. Science 224: 452-459.

12. Koenig JI, Snow K, Clarke BD, et al. (1990) Intrinsic pituitary interleukin- $1 \beta$ is induced by bacterial lipopolysaccharide. Endocrinology 126: 3053-3058.

13. Pernicone PJ, Scheithauer BW, Horvath E, Kovács K. (1992) Pituitary and sellar region. In: Sternberg SS (ed). Histology for Pathologists. Raven Press, New York, pp. 279-299.

14. Sapolsky R, Rivier C, Yamamoto G, Plotsky P, Vale W. (1986) Interleukin-1 stimulates the secretion of hypothalamic corticotropinreleasing factor. Science 238: 522-524.

15. Uehara A, Gottschall PE, Dahl RR, Arimura A. (1987) Interleukin-1 stimulates ACTH release by an indirect action which requires endogenous corticotropin releasing factor. Endocrinology 121: 1580-1582.

16. Sharp BM, Matta SG, Peterson PK, Newton R, Chao C, McAllen K. (1989) Tumor necrosis factor- $\alpha$ is a potent ACTH secretagogue: comparison to Interleukin-1 $\beta$. Endocrinology 124: $3131-3133$.

17. Spangelo BL, Judd AM, Isakson PC, MacLeod RM. (1989) Interleukin-6 stimulates anterior pituitary hormone release in vitro. Endocrinology 125: 575-577.

18. Elenkov IJ, Kovács K, Kiss J, Bertók L, Vizi ES. (1992) Lipopolysaccharide is able to bypass corticotrophin-releasing factor in affecting plasma ACTH and corticosterone levels: Evidence from rats with lesions of the paraventricular nucleus. Endocrinology 133: 231236. 